\title{
Chile's new middle classes: a cohort analysis
}

\author{
Oscar Mac-Clure
}

ABSTRACT

A cohort analysis methodology is used in this article to study Chile's "new" middle classes. It describes the members of these cohorts and compares them with older cohorts that are still economically active. The relative size as of the 1990s and 2000s of these occupationally determined middle classes or strata are analysed, and a distinction is drawn between "new" and "old" cohorts. The question as to whether or not the emergence of new occupational cohorts correlates with differences in income is also explored. This analysis leads to the conclusion that a new middle class has taken shape that is composed of people who became full-fledged members of the labour force during the economic growth surge of the 1990s and 2000s. The upper stratum of these new middle classes occupies a preeminent position, and social class influences income levels. 


\section{I}

\section{Introduction}

More and more attention is being focused on the middle classes in Latin America owing to concern about the persistence of poverty and social inequalities. The middle class also symbolizes a promise, of a sort, for large sectors of the population as their consumption levels rise (Franco, Hopenhayn and León, 2010). In terms of power politics in Latin America, in general, and in Chile, in particular, the sociopolitical matrix in place for much of the twentieth century has now been supplanted by one in which the economy is relatively independent of politics. This hinders the emergence of social classes -such as the working classes of past periods in history- that bring together large sectors of the population within the framework of predominant societal structures, as noted by Garretón (2007). The possibility exists, however, that the current social, cultural and political situation is being altered as "new" middle classes emerge, most of whose members belong to the younger generations. This is the line of thought that is explored in the present article.

In recent decades, as a corollary of the reduction in poverty, an "emerging" middle class has been making its appearance around the globe, including Latin America; but this new middle class is still at risk of slipping back down the income scale (Banerjee and Duflo, 2008; Kreckel, 2006; Ravallion, 2009; OECD, 2010). A specific case study of this emerging middle class in a country such as Chile has the potential to yield valuable findings. It must be noted, however, that -given how rapidly this change has been taking place- this process mainly involves the younger population, which is forming a new generation of the middle class. In addition, in past research the emphasis has been on studying the upward mobility of members of lower-income groups as they climb towards

$\square$ The Erikson/Goldthorpe/Portocarero (EGP) social class variable, as applied to surveys in Chile, was designed by Vicente Espinoza, for whose support I am sincerely grateful. I also wish to thank José Pujol for his contribution to cohort analysis, Álvaro Krause for his assistance in calculating Gini coefficients, and Víctor Maturana for his work on the regression model. I am also grateful for the valuable comments made by Emmanuelle Barozet, Gonzalo Delamaza, Vicente Espinoza, Arturo León and Javier Núñez. This article is one of the outputs of the Anillos SOCI 2 Project, which is part of the Inequalities Project funded by the National Commission for Scientific and Technological Research (CONICYT). positions in the middle class, but much less attention has been devoted to what has been happening in the rest of the middle classes, and particularly in the upper reaches of this income group. This article will therefore look at all the members of these middle classes, rather than focusing on just one sector within this catergory.

As noted by Bourdieu (1987), it can be posited that positions near the middle of the spectrum are associated with an indeterminate ("intermediate") economic and cultural status in any given period, but they also change over time. The future positions of persons in the middle class are fairly certain to be either higher or lower than their present positions. This means that we can draw a distinction between descending intermediate positions and those that are stable or ascending. Bourdieu reasons that the intermediate positions that offer a more secure future are those occupied by the persons making the greatest effort to move up the ladder - the future members of a "new" middle class. Focusing on the future of these new middle classes, rather than on what is happening at any given point in time or time period, Bourdieu attributes special importance to the particular features of different generations. This analysis will therefore seek to identify the upwardly and downwardly mobile sectors within the new generations of the middle classes.

The term "generation", as used here in a sociological sense to allude to the idea of a new middle class, dates back to the theory of generations developed by Mannheim (1952), who maintained that if individuals are in the same stage of the life cycle (e.g., if they were born in the same year), they will be influenced in similar ways by their societal environment and changes in economic and social conditions. Their membership in the same generation will mean that the gateways through which they can enter into various spheres of society will be similar. By way of illustration: people who were born in the same year, who enter the labour market at more or less the same time and whose level of education is similar will share fairly well-defined options that will differ from those open to people who do not have these characteristics.

The more specifically defined concept of a "cohort" (Ryder, 1965; Glenn 2005) provides a way of observing individuals who share a given initial characteristic (such as the same year of birth) and monitoring that group with the help of quantitative data in order to 
gauge the impact on its members of one or more events over time. ${ }^{1}$ The concept of cohorts has been used in studies of middle classes in other countries (Chauvel, 2002) and is employed in the new approach that will be proposed here for the quantitative analysis of data from the National Socio-economic Survey (CASEN), the main household survey conducted in Chile, for 1990 2009 (Ministry of Social Development (formerly the Ministry of Planning and Cooperation)). Studying these "new" cohorts of the middle class, whose members - unlike the members of "old" cohorts- still have many of the stages in the life cycle ahead of them, can offer something that methodologies based on populationwide data cannot: a systematic analysis of the path that this class may follow both now and in the future. In a broader sense, studying the cohorts making up the Chilean middle classes may contribute to a better understanding of these classes and of the associated inequalities and social processes.

1 The cohort analysis methodology was initially developed for use in demographic studies and is now widely used in fields such as medicine and education.
In Chile, market liberalization, the growth of tertiarysector jobs and the spread of education have influenced the composition of social classes and opportunities for social mobility (León and Martínez, 2001; Torche and Wormald, 2004). This gradual process continued to unfold as the country transitioned from a period of economic stagnation and instability to one of relatively rapid growth in the 1990s and 2000s. The hypothesis on which this study is based is that this had a different influence on cohorts whose members began their working lives during those two decades than it did on people who had done so earlier. The argument is made here that the changes in employment and income generated by rapid economic growth during those two decades had a stronger influence on the more recent cohorts of the middle class -those that became active members of the labour market during that period- than on the older members of the middle class.

Following this introduction, the article is structured as follows. Section II covers the change in focus from the middle class to the middle classes. Section III focuses on middle-class cohorts during a period of economic growth. Section IV looks at middle-class cohorts from the standpoint of income inequality and meritocracies. Section V concludes.

\section{II}

\section{From the middle class to the middle classes}

In order to take a close look at the middle class, given its heterogeneity, we actually have to think in terms of the middle classes. One way of defining these classes and distinguishing between them is by looking at sets of traits, such as occupation, income and consumer goods in the home. This approach has been used to describe these classes in Chile and elsewhere in Latin America (Franco, Hopenhayn and León, 2011). For the cohort analysis being undertaken here, the focus will be on the different types of work that members of the middle classes do, since this factor strongly influences their income levels, lifestyles and cultural identities.

Viewed from this occupational perspective, class structure can be studied on the basis of various types of classifications. ${ }^{2}$ Primarily in order to maintain comparability, the classification developed by Erikson

2 For a thorough discusión of the mostly frequently used classifications, see Leiulfsrud, Bison y Jensberg (2005). and Goldthorpe (1993) will be used here, since it is one of the most widely used systems both internationally and in recent major studies in Chile (Torche and Wormald, 2004; Espinoza and Barozet, 2009). In this occupationbased typology, categories are established on the basis of a combination of three criteria: ownership and control of means of production, the provision of services on a more or less autonomous basis, and the performance of skilled or unskilled manual work. Specific occupations are classified as falling into one or another social class, with those classes being defined on the basis of the above criteria, by referring to a combination of the variables on which employment statistics provide information: occupational category, economic activity, trade or profession, and company size.

Large- and medium-scale entrepreneurs, who accounted for $1.2 \%$ of all employed persons in 2009 , will be excluded from the analysis because, if they were to be included, it would be necessary to measure their capital income, and the Chilean household surveys used 
in this study do not provide accurate data on that income category. ${ }^{3}$ Apart from this group, the social classes in the country, defined on the basis of the Erikson and Goldthorpe classification, are shown in figure 1 , which gives the percentage of employed persons in each class as of 2009.

Using the dividing line generally employed in studies on the subject, the middle classes are defined as being composed of the persons in the first four categories of non-manual workers in the classification system shown in figure 1 ( $54 \%$ of the employed persons in the country).

The services class is the first group of occupations associated with the middle classes. The top rung of the ladder is primarily occupied by professionals and highlevel technical personnel working as business executives in the private sector or as officials holding leadership or senior management posts in the public sector. The next rung down is occupied chiefly by professors, professional administrative staff, highly trained technical personnel, mid-level health professionals and professional staff in the field of communications. Most of these people have a higher education and perform economic activities in the services sector, although some are employed in other areas.

3 For the purposes of this study, large- and medium-scale entrepreneurs are defined as those who were reported as being employers or owners of businesses with 10 or more workers in the 2009 CASEN survey.
The second group included in the middle classes is made up of people who perform routine, non-manual tasks. These people often have jobs as high-level salespersons and administrative staff or, at a lower level, as secretaries or cashiers. Most of these wage earners have not gone beyond high school, and very few of them have completed their university education.

Independent or self-employed workers who are neither professionals nor trained technicians (mainly vendors at kiosks, market stands and grocery stores, taxi drivers, carpenters, seamstresses and tailors, hairdressers, garage mechanics, woodworkers and other craftspeople who employ traditional techniques in their work, etc.) are also considered to be part of the middle classes. Their occupations are ones that require more experience than formal education. About half of these people have at least completed their secondary education, but the other half have not. Many of these people work in what is known as the "informal" sector, to judge by the fact that most of them do not pay into the social security system. Given that their independent or non-wage-based activities are a distinctive feature of this middle-class group, their situation can be likened to those in the category that has traditionally been referred to as the "petit bourgeoisie", along with small-scale entrepreneurs. This latter -and comparatively smaller- category of

FIGURE 1

Social classes in Chile: percentages of total employed
persons between the ages of 25 and 65,2009
(Percentages, excluding large- and medium-scale entrepreneurs)

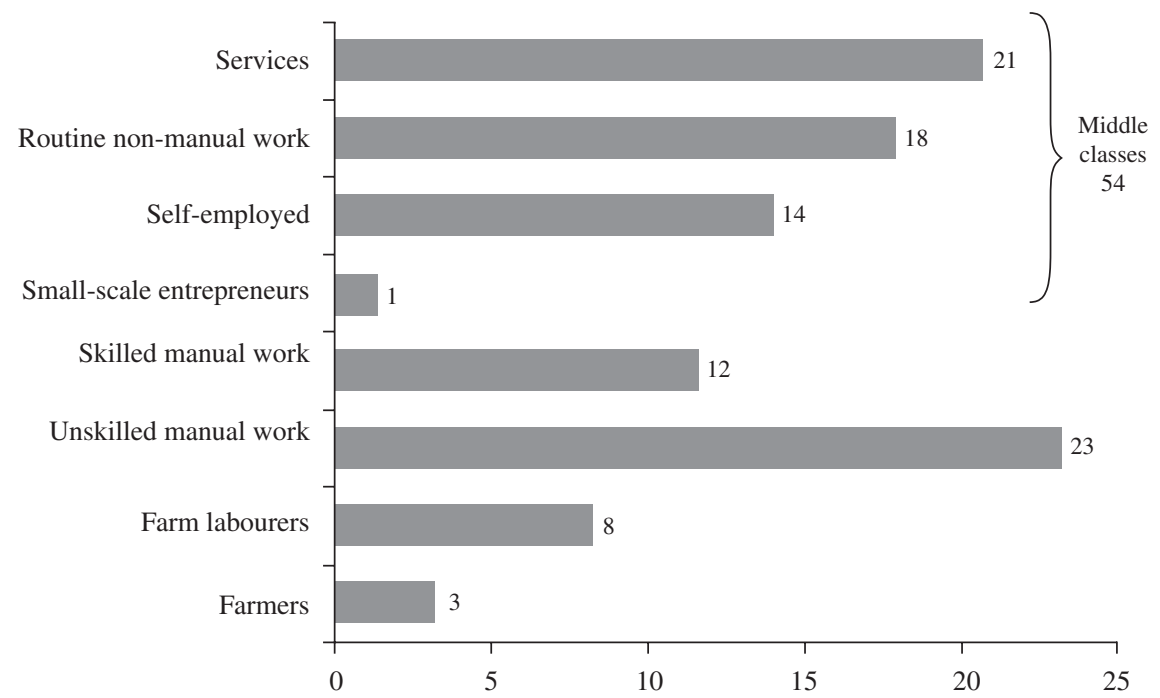

Source: 2009 National Socio-economic Survey (CASEN). 
small-scale entrepreneurs is composed of those who employ between two and nine workers and constitutes a fourth stratum within the middle classes. ${ }^{4}$

When the occupation-based criterion is used as the only dividing line, then the categories of skilled and unskilled manual workers are not included in the middle classes. Wage earners engaged in manual work do not fit the conventional definition of the middle class, although many of them may self-identify or be identified as members of the middle -as opposed to the "lower"- class. Wage earners engaged in skilled manual work include mechanics, cooks and solderers, while wage earners engaged in unskilled work include less-skilled construction workers,

4 This inevitably arbitrary cut-off point for the number of wage earners corresponds to the internationally defined range based on the EGP stratification scale, as do the other definitions used in our classification. These numbers of employees per firm also correspond to the usual method for classifying small-scale employers based on CASEN data. truck drivers, security guards, janitorial staff and domestic service workers. Unskilled manual workers make up the largest occupational group in the country and, although they are not included in the middle classes, they must nevertheless be taken into account in the analysis for reasons that will be discussed below.

The last two categories are those of farm labourers and farmers, who, because of the economic activities in which they are engaged (regardless of their subjective view of themselves as members of the lower, middle or upper class) are not defined as belonging to the middle classes because of their non-urban character.

It is a known fact that the expansion of economic activities in service industries and commerce has led to an increase in middle-class occupations associated with services and routine non-manual tasks, but it is not known how much of this increase has taken place in more recent or older cohorts. This question will be explored in the following section.

\section{III}

\section{Middle-class cohorts in a period of rapid economic growth}

The next step is to undertake a cohort analysis in order to distinguish "new" cohorts from "old" ones in the middle classes as defined above. Finding out how the new middle-class cohorts have fared during the period of relatively rapid economic growth seen during the 1990s and 2000s may provide a new and interesting perspective on the subject, as will be seen in the following dicussion.

This analysis starts off with the assumption that variations in the share of total employment accounted for by one or another cohort are attributable to structural changes that impact social classes. According to Bourdieu (1987, p. 350), quantitative downward movements generally reflect an economic and social decline. In other words, they are linked to a past situation that no longer exists or is on its way to disappearing. Conversely, upward mobility is associated with occupations that are the way of the future. Thus, in the past, Weber (1964, pp. 244 and 245) noted that the transition of craftspeople to membership in the "independent petit bourgeoisie" represented an "ideal" for manual workers, but this ceased to be a viable opportunity as middle-class ococupational groups such as office workers and bureaucrats expanded.
In order to take a closer look at the current situation in Chile, we will analyse middle-class cohorts based on their year of birth using the CASEN survey data compiled during the period of economic growth of interest to us here (the 1990s and 2000s). ${ }^{5}$

A classic Lexis diagram is used for the cohort analysis since, thanks to the existence of representative population surveys such as the CASEN series, data are available on people in the same cohort (i.e., people who were of a given age when the first survey was conducted in 1992 and who were 17 years older when the 2009 survey was taken). ${ }^{6}$ By way of example, people who were 25 years of age in 1992 had been born in 1967 and were 42 years of age when the 2009 survey was conducted (based on the assumption that the survey respondents

\footnotetext{
5 Data from the CASEN surveys conducted in 1992, 1994, 1998, 2000, 2003, 2006 and 2009 have been used for this cohort analysis.

6 The Lexis diagram provides a means of portraying population dynamics. It can be used to plot two dimensions of time: the dimension of calendar time and the temporal dimension represented by the ages of individual people. This combination gives rise to a third temporal dimension: the life line of a cohort, baed on the year of birth or any other relevant event.
} 
in each of those years are generally representative of the people born in that same year and therefore belong to the same dummy cohort). The use of this method for all the surveys constitutes a departure from the usual approach, which involves setting age groups based on the ranges of ages in a series of surveys.

The following figures graph out the findings arrived at using this method. The percentages denote the relative size of the groups belonging to a given class as compared to the total number of employed persons of the same age (at the time that they were surveyed). Middle-class cohorts are identified according to their members' year of birth, and each graphed line represents a cohort. In order to simplify the analysis and mitigate reporting errors, this exercise is based on the percentages for five-year age groups for the bulk of the population and for three-year age groups for the youngest and oldest members (from 25 to 27 years of age and from 63 to 65 years of age). Thus, for example, each point shown on the graph for 30-year-olds corresponds to the percentage of employed persons between the ages of 28 and 32 . The population under analysis is composed of employed persons between the ages of 25 and 65 at the time that each of the CASEN surveys was conducted.

The results obtained for the upper stratum (i.e., services) of the middle classes using this methodological approach are illustrated in figure 2.7

FIGURE 2

Services class: percentage of employees, by age and cohort, 1992-2009

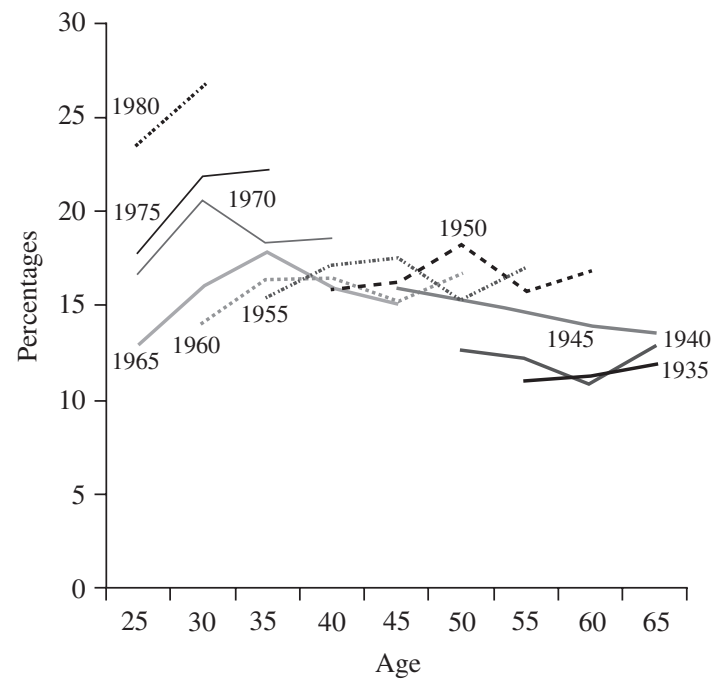

Source: National Socio-economic Survey (CASEN), 1992 - 2009.

7 The upper and lower strata of the services class have been added together because the results for the two are very similar.
The cohort effect is clear to see in the services class, as shown in figure 2. A larger percentage of the members of the younger cohorts, particularly those corresponding to $1970-1980$, belong to this upper stratum within the middle class than is true of the members of older cohorts. At a given age (e.g., 30 years of age), a larger percentage of employed persons in the country from the 1970 cohort belonged to the services class than was true of the 1965 cohort. This change or cohort effect is not very noticeable after the 40 -years-of-age mark, but a difference in the oldest cohorts can still be discerned.

By contrast, in the self-employed class, both the age-based progression and the share of new cohorts in total employment differ from what they were in the services class, as shown in figure 3 .

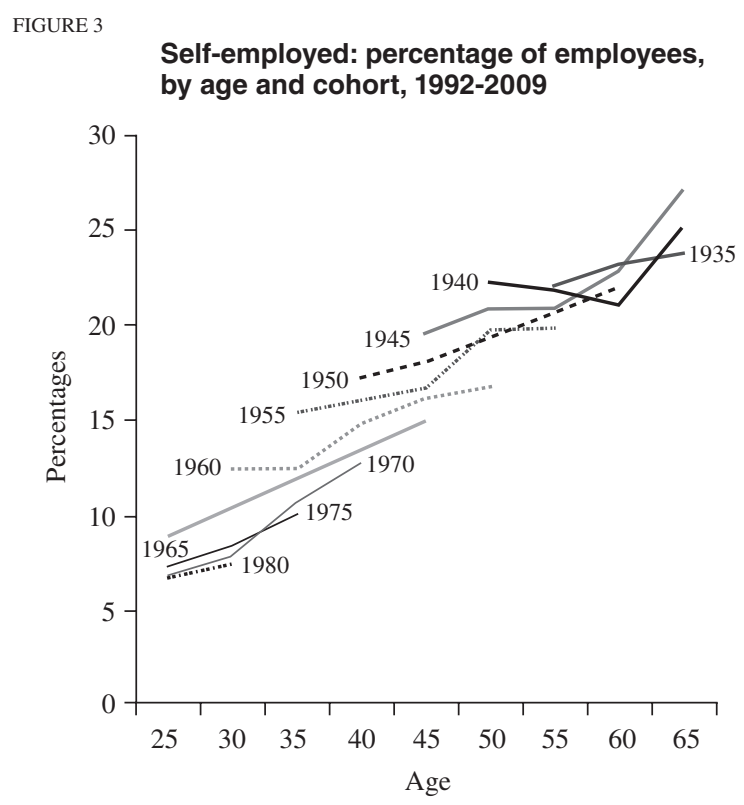

Source: National Socio-economic Survey (CASEN), 1992 - 2009.

Unlike what was observed in the case of the services class, self-employment increases with age, although less markedly in the younger cohorts (persons born around 1970 or more recently), as shown in figure 3. It is especially interesting to note that, unlike the results obtained for the services class (see figure 2), in which the percentage of younger cohorts expanded at the same age, the percentage of those same cohorts in the selfemployment class (see figure 3 ) shrank quite markedly.

In a trend that is just the reverse of the one seen in the case of self-employed persons, a declining age-based 
progression is seen in the category of routine non-manual work; this progression is also the same across the different cohorts, as shown in figure 4.8

FIGURE 4

Routine non-manual work: percentage of employees, by age and cohort, 1992-2009

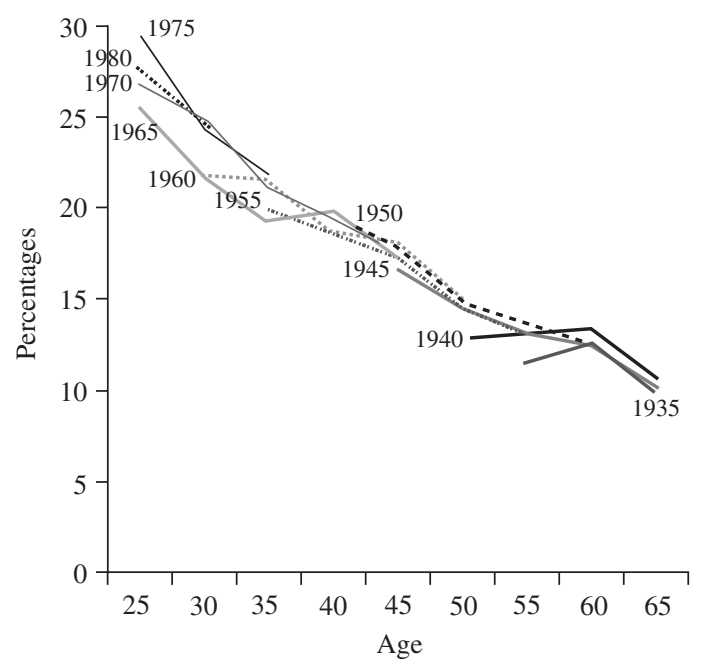

Source: National Socio-economic Survey (CASEN), 1992 - 2009.

As the age of survey respondents rises, the proportion of them who are engaged in routine non-manual tasks declines, and this occurs at a fairly even pace across the various cohorts, including the youngest ones, as may be seen from figure 4 . In the younger cohorts, the age effect is stronger than the cohort effect.

Unlike what we saw in the case of the services class, the percentage accounted for by younger cohorts holds steady in the routine non-manual class. This is also a departure from the trend in the self-employment class, where the percentage declined. A change in the composition of the middle classes can be observed, particularly in the services class, whose membership is larger in the cohorts corresponding to people born between 1970 and 1984, according to the quinquennial data. When annual data are used, it can be seen that the turning point for the services class is clearly situated in 1971 .

Strictly from the standpoint of quantitative differences, the larger size of the services class among younger cohorts is partially attributable to the shrinking

8 The upper and lower strata in the routine non-manual category exhibit similar trends. number of members of these cohorts who are selfemployed and to a smaller decrease in the proportion of members of these same cohorts that are employed as unskilled manual workers.

Viewed from the standpoint of intergenerational social mobility, this could be interpreted as a transition that starts with the parents and continues on with their children. On the one hand, upwardly mobile people are rising up to the services class and, on the other, there is an inflow of people from outside the middle classes into the category of routine non-manual work. Some $60 \%$ of the younger cohorts in the routine non-manual class have parents who belong to the class of manual workers. By contrast, approximately $59 \%$ of the parents of members of the younger cohorts in the services class also belong to that class or some other stratum of the middle classes, and the parents of the rest belong to the manual worker or farmer categories. ${ }^{9}$ A portion of the younger middle-class cohorts thus consists of members of an "emerging" sector who are seeking better options than the manual work performed by their parents and who succeed in gaining entry to the routine non-manual stratum of the middle classes; there is also, however, an upwardly mobile group that seizes the opportunity to bypass this stratum and to gain entry into the services class. The size of the routine non-manual category thus does not increase in the younger cohorts, as the upwardly mobile sector succeeds in differentiating itself from this stratum and becoming part of the services class. In addition, members of the younger cohorts distance themselves from the type of self-employment engaged in by their parents and instead become part of the emerging or upwardly mobile sectors.

The results of this cohort analysis of the middle class contribute two additional elements to this intergenerational explanation. First, the transition taking place in upwardly mobile and emerging sectors is an inherent aspect of the younger middle-class cohorts, since the changes that we have been discussing occurred more intensively in these cohorts than in older ones in the 1990s and 2000s. Consequently, contrary to what one might expect, this is not a phenomenon that is seen throughout the middle classes. Second, although the expansion of consumption may tend to focus our attention on the appearance of an emerging middle class whose members are drawn from

9 These figures are based on an analsyis of the data furnished by the National Social Stratification Survey conducted by the Inequalities Project (Anillo SOCI2) of a nationally and regionally representative sample of the population in 2009. The figure given for parents engaged in manual work includes farm labourers. 
the lower classes and from sectors living in poverty or in socially vulnerable situations, transitions of this type also involve upwardly mobile groups within the younger cohorts of the middle classes that are moving into the upper strata of these classes and swelling the ranks of the services class, as noted earlier.

It should be emphasized that the results of this analysis refer solely to the situation in the 1990s and 2000s and therefore do not relate to family lines or long-term processes - and therein lies their potential contribution to an explanation of long-term trends. As we have seen, if we look at groups whose participation in the labour market has increased during the review period, the results show that the newer middle-class cohorts are chiefly composed of people born from 1970 on who belong to the services class, which acts as a driving force. This influences the internal dynamics of the stratum of the middle classes engaged in routine non-manual work and, more broadly, the new middleclass cohorts as a whole.

The findings of this analysis indicate that cohorts whose members were born from 1970 on have a different class structure than earlier cohorts. This inflection point is located at the point on the spectrum marking the cohorts whose members were born in or after 1970 and who thus have turned 25 years of age since 1995 . This means that they entered the labour market on a full-time basis during the economic boom of the 1990s and 2000s, and this is a defining characteristic of the new middle-class cohorts. The economic growth that occurred during this period heightened the changes taking place in the employment structure as the importance of different economic activities shifted. All of the Latin American economies have witnessed an expansion of the tertiary sector along with a contraction of the industrial and agricultural sectors. The additional information that this middle-class cohort analysis provides is that these changes have been more significant in newer cohorts than in older ones.

In terms of the size of the new cohorts, this finding is not trivial, since people born in 1970 on went from accounting for $7 \%$ of the middle classes in 1996 to $44 \%$ in 2009.

The results point to a recent shift in the make-up of the middle classes from the standpoint of their component cohorts. The next question is whether we are simply dealing with a change in the composition of the middle classes or whether, in line with the classical school of thought regarding social classes as espoused by Marx and Engels (1989) and Weber (1964), the important point is to determine whether this entails inequalities in terms of access to economic resources and income distribution.

\section{IV}

\section{Middle-class cohorts, income inequality and meritocracy}

In order to determine whether the trends discussed thus far denote seomthing more than a change in the occupational structure, the next step is to find out whether new cohorts' membership in the middle classes correlates with differences between their and older cohorts' income levels. We will seek to determine whether inequality increases or decreases in new cohorts and what factors influence how much they are paid.

The most widely accepted indicator of income distribution in empricial studies is the Gini coefficient. The available data can be used to compute this indicator for employed persons as a whole with a view to determining whether there is greater or less inequality in the two agebased groups of cohorts that we have been examining.
The data will not be disaggregated further than this in order to avoid problems of statistical representativity. The Gini coefficient distribution of the earned (labour) personal income of employed persons, by age, for the new and older cohorts is shown in figure 5.10 As the

\footnotetext{
10 Problems of statistical representativity -which place a limit on how much data can be disaggregated-arise as a result of the fact that the first step is to calculate a Gini coefficient for all the people of each age (one-year age groups) for each survey. In order to lessen the statistical error that this procedure generates, moving averages for five-year age groups have been used to calculate the Gini coefficients for each one-year age group for all the surveys covered by this analsyis. Simple averages of the Gini coefficients for the one-year cohorts are then reported for the younger and older cohorts.
} 
newer cohorts are composed of people who were born in 1970 or later, they included people of up to 39 years of age at the time of the 2009 survey. This is therefore the upper age limit for the comparison.

FIGURE 5

Gini coefficients for employed persons, by age a and by membership in new or old cohorts,b 1990-2009

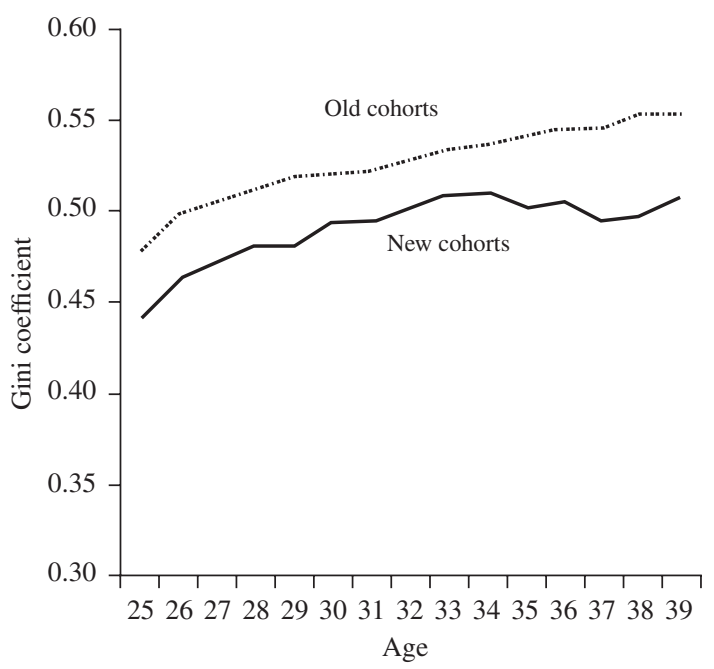

Source: National Socio-economic Survey (CASEN), 1992 - 2009. Note: Earned personal income corresponds to the YAUTAJ variable used in CASEN surveys.

a Gini coefficients caculated as moving averages of earned personal income for persons between 25 and 39 years of age.

b New cohorts: Persons born in 1970 or later. Old cohorts: Persons born before 1970 .

Income inequality as measured by the Gini coefficient is, in general, fairly low for younger persons and rises with age, although it does tend to level off somewhat in the newer cohorts, as shown in figure 5. In addition, the Gini coefficients of the newer cohorts are lower than those of the older cohorts, with an average differential of 0.04 points of the coefficient. This is in line with what Sapelli (2011a) has found to be the case for the Chilean population as a whole. In other words, there has been a change in the overall trend with regard to newer cohorts, which are subject to less inequality at the same age than earlier cohorts were. For example, for the period from 1990 to 2009, the Gini coefficient was 0.53 for employed persons aged 35 in the cohort of persons born before 1970, whereas it is only 0.50 for persons aged 35 who were born after that year. Here, we have calculated the average Gini coefficient during the review period for the two groups of cohorts between which we have drawn an empirical distinction (i.e., those born before 1970 and those born in 1970 or later), but if the coefficients are computed for each one-year age group, then the sharpest jump is seen in the group of people born in 1971 .

The fact that the Gini coefficient is lower for persons of all ages in the new cohorts than it is for people in the old cohorts (see figure 5) corroborates the validity of the distinction made between these two groups of cohorts, since this reflects a clear-cut cohort effect rather than just an age effect. This statement applies to employed persons as a whole; we cannot make it specific to the middle classes because of the problems of statistic representativity mentioned earlier. However, later on we will come back to this point and look at the effect on income of membership in each of the strata of the middle class, both for the new and the older cohorts.

The search for an explanation for the lower degree of income inequality found in the newer cohorts gives rise to two types of discussions regarding the middle classes. First, from an inter-cohort standpoint, one question to be asked is whether this lower degree of inequality may be at least partly attributable to the upward transition to employment in the services sector seen in these cohorts, which are chiefly composed of people who have completed their university or technical education. In theory, this opens the way for an equalizing, "meritocratic" effect (a possibility that will be explored later on), especially when higher education is within the reach of people not belonging to elite groups - which has increasingly been coming to be the case in Chile for several decades now. Second, the question arises as to what the main causes of the lower degree of inequality observed in the new cohorts may be.

The trend in the Gini coefficient, by cohort, in recent years (see figure 5) also poses a more general problem in connection with the level of inequality that it reflects, since even in the new cohorts, the coefficient is still quite high - far higher, for example, than the average Gini coefficient of 0.31 of the OECD countries (OECD, 2011). Thus, income inequality in the new cohorts is far from satisfactory, as noted by, for example, Sapelli (2011b). The expansion of the services class within the new cohorts has thus not led to any substantial reduction in inequality. This raises a question as to the effectiveness of education as an equalizing factor and, even more generally, as to the reasons why the level of inequality remains so high in both groups of cohorts. 
Without seeking to establish any direct causal relationship between trends in the Gini coefficients for Chilean society as a whole and trends in the middle classes, the above opens up a number of avenues for exploration and points up the importance of taking a closer look at the inequalities existing in the new cohorts of the middle classes.

Maintaining the definition of new cohorts as those born in 1970 or thereafter, we will undertake an empirical analsyis of the differences in the income levels of new and older middle-class cohorts, with the focus being on determining which factors play a role in those inequalities and how closely they may or may not be aligned with membership in the middle classes. A multiple linear regression model -similar to the one employed by Leiulfsrud, Bison and Jensberg (2005) in studying the employed population of the European countries- can be used for this purpose. This will allow us to control for the effect of variables known to influence income, such as education and work experience, whose impact was originally postulated by Mincer (1974) and Becker (1975).

This regression model provides us with a picture of how important membership in a given social class is in determining the incomes of persons of the same sex who have the same number of years of work experience and a similar level of education (without considering any of the interactions among these variables). More specifically, the results given in table 1 refer to a benchmark income level that corresponds to the average earned income of a man who has not finished his basic education and who belongs to the class of unskilled manual workers. The computation is performed for members of the older cohorts (born between 1944 and 1969) and for members of the new cohorts (born between 1970 and 1984). ${ }^{11}$ The results correspond to each of the CASEN surveys conducted in 1998 - 2009.

\footnotetext{
11 A similar exercise could be performed using the same linear regression for all the data, without dividing cohorts into separate groups, by adding a dummy variable that distinguishes between younger and older cohorts. However, this would mean that we would have to specify the age groups corresponding to those cohorts for each survey, a non-independent subset or combination of experience-related variables (as well as age data), which would mean that the high correlation to be expected among these variables would invalidate the results for each variable.
}

\begin{tabular}{|c|c|c|c|c|c|c|c|c|c|c|}
\hline & \multicolumn{5}{|c|}{ Born between 1944 and 1969} & \multicolumn{5}{|c|}{ Born between 1970 and 1984} \\
\hline & 1998 & 2000 & 2003 & 2006 & 2009 & 1998 & 2000 & 2003 & 2006 & 2009 \\
\hline Women & -0.25 & -0.24 & -0.24 & -0.27 & -0.26 & -0.25 & -0.25 & -0.24 & -0.29 & -0.26 \\
\hline Apparent experience (age-years of school-6) ${ }^{b}$ & 0.34 & 0.28 & 0.29 & 0.26 & 0.21 & -0.09 & 0.08 & 0.13 & 0.18 & 0.15 \\
\hline Apparent experience squared & -0.26 & -0.17 & -0.24 & -0.24 & -0.23 & 0.01 & -0.07 & -0.10 & -0.12 & -0.09 \\
\hline Completed basic education & 0.08 & 0.10 & 0.09 & 0.09 & 0.08 & 0.03 & 0.06 & 0.06 & 0.07 & 0.07 \\
\hline Incomplete basic education & 0.16 & 0.17 & 0.15 & 0.15 & 0.12 & 0.08 & 0.13 & 0.13 & 0.13 & 0.11 \\
\hline Completed secondary education & 0.27 & 0.29 & 0.27 & 0.24 & 0.22 & 0.18 & 0.27 & 0.27 & 0.28 & 0.27 \\
\hline Incomplete technical or university education & 0.18 & 0.16 & 0.16 & 0.14 & 0.12 & 0.13 & 0.16 & 0.19 & 0.19 & 0.17 \\
\hline Completed technical or university education & 0.41 & 0.38 & 0.41 & 0.35 & 0.30 & 0.27 & 0.37 & 0.40 & 0.40 & 0.39 \\
\hline Services & 0.21 & 0.20 & 0.20 & 0.20 & 0.21 & 0.31 & 0.28 & 0.31 & 0.28 & 0.30 \\
\hline Routine non-manual work & 0.12 & 0.11 & 0.10 & 0.12 & 0.14 & 0.21 & 0.19 & 0.16 & 0.17 & 0.18 \\
\hline Small-scale entrepreneurs & 0.19 & 0.17 & 0.19 & 0.17 & 0.16 & 0.14 & 0.11 & 0.15 & 0.13 & 0.12 \\
\hline Self-employed & 0.26 & 0.21 & 0.23 & 0.23 & 0.27 & 0.25 & 0.19 & 0.21 & 0.19 & 0.22 \\
\hline Skilled manual workers & 0.09 & 0.11 & 0.10 & 0.13 & 0.13 & 0.14 & 0.13 & 0.15 & 0.16 & 0.16 \\
\hline Farm labourers & 0.02 & 0.06 & 0.04 & 0.07 & 0.09 & 0.05 & 0.07 & 0.06 & 0.07 & 0.08 \\
\hline Farmers & 0.12 & 0.10 & 0.14 & 0.17 & 0.17 & 0.10 & 0.07 & 0.10 & 0.11 & 0.12 \\
\hline
\end{tabular}

Source: 2009 National Socio-economic Survey (CASEN).

Note: The dependent variable corresponds to the logarithm of earned individual income. Earned personal income corresponds to the YAUTAJ variable used in the CASEN surveys.

Large- and medium-scale entrepreneurs (employers or owners of businesses in the services class) are excluded from the analysis. The results are statistically significant at $1 \%$ for all variables in both cohorts and for all years, with the exception of the variables for work experience in the new cohorts of the 1998 CASEN survey.

a New cohorts: People born in 1970 or later. Old cohorts: People born before 1970 .

b Apparent experience is calculated as age-years of school- 6 . 
The results shown in table 1 indicate that completion of a higher education is generally the factor that has the greatest influence on income levels, but the explanatory factors are not limited to education and years of work experience; social class also has a considerable impact. This finding is significant, because it means that being a member of the middle classes is also a substantive determinant of people's earned income levels. In addition, the earned income levels of members of the middle classes are fairly similar in that they are consistently higher than the incomes of unskilled manual workers. Nonetheless, the incomes of members of the routine non-manual occupational category are relatively closer to those of unskilled manual workers. All of these proportional differences remain in evidence and the variables continue to be statistically significant when the same linear regression is applied to the entire employed population between the ages of 25 and 65, with no distinction being made between different cohorts.

The results provided by an inter-cohort comparison of newer and older cohorts are particularly informative for the purposes of this study. As shown in table 1, class membership has a stronger relative impact on income levels among the new middle-class cohorts in the services and routine non-manual occupational categories than it does among the members of older cohorts.

Within the new cohorts, the incomes of members of the services class are strikingly higher than those of members of other middle-class strata and especially so compared to the incomes of manual workers. In other words, the occupational status of people in the services class in the new cohorts gives them access to clearly more advantageous earning opportunities.

From an intra-cohort perspective, the income trends for the new cohorts are particularly informative, since they not only trace past circumstances but also point the way towards possible future trends. One very interesting aspect is the possibility of seeing how the impact of having a higher education and the effect of membership in the services class have changed over time, since these variables have, as we have seen, played a very important role during the review period. The results relating to these factors are graphed in figure 6.

As can be seen from figure 6 , in the case of newer cohorts, the income effect of having completed a university or technical education increased, in percentage terms, up to the early 2000s relative to the average pay levels of unskilled manual workers who had not completed their basic education. Since then, however, the effect of this variable has levelled off or even weakened as the number of graduates from universities and high-level technical instititues has risen. In other words, the well-known phenomenon by which the value added by education is devalued as education becomes available to the population at large has been at work. In contrast, membership in the services class continues to have a strong influence on income levels, although it fluctuates somewhat. These results make it possible to measure the effect of having completed a course of higher education; this could be analysed further to determine cross-university or crossinstitution differences in terms of quality and prestige, as well as differentials in access to a high-quality education linked to the parents' class origin.

\section{FIGURE 6 \\ Relative income effect of completed higher education and membership in the services class for new cohorts, 1998-2009 (Percentages)}

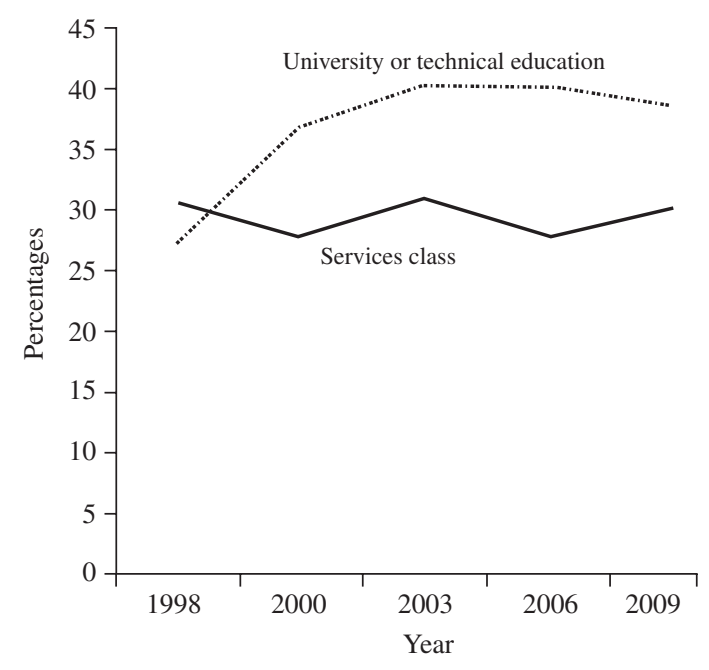

Source: original calculations on the basis of data presented in table 1.

Since, for the new cohorts in the services class, the simple fact of possessing a university degree has been devalued, the possession of a job in the services sector has come to have a greater influence on income levels, as is shown in figure 6 . This is part of the reason why the level of income inequality remains high despite the spread of higher education, even in the new cohorts of the employed population, as is demonstrated by the Gini coefficients for these cohorts shown in figure 5. If a person hopes to earn a higher income, then that person will need to have, in addition to a degree, contacts with persons employed in the services class. The ability to make contact with people in that class can depend on such factors as having had a high-quality secondary education, having attended a prestigious university, having a means of networking with them (having "social capital", in the broad sense of 
the term) (Barozet, 2006) and even having the ability to share certain cultural referents (i.e., "cultural capital) in a general sense. In addition, the ongoing incorporation of technological change spurred by the new information and communications technologies (ITCs) that are an inherent part of the globalization process is more readily embraced by more highly educated people than by persons with no more than a secondary school education who perform routine tasks in their jobs. This has the effect of heightening income inequalities (Mac Clure, Katz and Krueger, 2008) and calls for a discussion of the question as to what point this perpetuates inequalities within new cohorts and as to whether, regardless of the type of formal education initially received, the pace at which technological change is absorbed speeds up for people who are already employed in the services sector.

The results indicate that the income differential based on membership in different social classes remains in effect for most of the members of new middle-class cohorts and that it is actually greater in those cohorts than in the older cohorts in these intermediate categories (with the exception of self-employed persons and smallscale entrepreneurs). Membership in the new cohorts of the middle classes does appear to make a difference in terms of income, and this effect does not appear to be on the decline. This aspect is also closely related to the composition of the new cohorts, as discussed earlier. The

\section{V}

\section{Conclusions}

The economic and social developments within Chilean society witnessed in the last two decades have generated a change in the middle classes. The cohort analysis performed in this study provides evidence of the emergence of a new middle class which is populated by people who were born in 1970 or later and who became full-fledged members of the labour force during the time of strong economic growth seen in the 1990s and 2000s. This pattern and the break in the trend that separates those born from 1970 or later from those born before that time constitute an informative contribution to the study of middle-class cohorts that has been made possible by the use of a cohort analysis methodology.

This cohort analysis also clarifies the fact that this process is not limited to the emergence of a middle class formed by people who would otherwise have been members of poorer classes; it must also be described in broader terms that encompass the various middle classes. It can relatively higher incomes of people in the services class are linked to the rising percentage of the more recent population cohorts that belong to that class. By contrast, members of the routine non-manual occupational category do not earn as much as people working in the services sector, nor are they increasing in numbers within the new cohorts. Thus, in these new middle-class cohorts, there is a clear correspondence between average incomes -according to the linear regression model-and increases or decreases in membership in the relevant class.

In sum, the results discussed here indicate that new cohorts of the middle classes are not simply an occupational category but instead, at least from the standpoint of income levels, share a number of characteristics that set them apart from other classes and from older cohorts of the middle class. In addition, income differences between members of these new middle-class cohorts correspond to their membership in one or another stratum of that class. Furthermore, among the new cohorts in the services class, which act as a driving force within the middle classes, social class is having a significant and growing relative impact on their income levels in recent years. This finding does not provide any evidence to support the idea that progress is being made towards an increasingly meritocratic society in which opportunities and income levels are primarily determined by educational level. be concluded that the services class occupies a preeminent position within the middle classes and specifically the new middle classes - a finding that contributes to a better understanding of today's middle class. Relative to total employment patterns in the country, the proportion of the new middle-class cohorts in the services class has expanded more than the proportions corresponding to other middleclass strata, making the services class the most dynamic component of the new middle classes. The income levels deriving from this class membership are higher than those of members of older cohorts who belong to the same class and than the incomes of members of other middle-class strata. In other words, the middle class in contemporary Chilean society is chiefly populated by a new class of professionals and trained technicians, most of whom have a higher education and work as employees of companies or institutions. This marks a "before" and an "after" in the Chilean middle class in terms of its component cohorts. 
Membership in the new middle classes, along with other factors such as level of education, influences people's income levels, and this finding contributes to a beter understanding of some of the causes of the income inequality that exists in Chielan society. In addition, the emergence of a new middle-class generation has social, political and cultural effects that may be beginning to influence the direction in which today's society is moving and the social movements that are taking shape.

The cohort analysis methodology employed in this study offers a systematic basis for gauging the possible current and future trajectory of the middle classes. It can be posited that the new middle classes share a generational set of circumstances that will induce them to seek out better opportunities in the face of the social inequalities generated by those who came before them. This serves to delimit the issue of collective forms of solidarity raised at the start of this article, although it does not resolve it, since the set of circumstances shared by the new middle classes is only the beginning of the generational issue -as characterized by Mannheim (1952)- surrounding the presence or absence of a bond based on a shared path. In particular, it remains to be determined whether this path will take society in the direction of a mesocracy (i.e., governance by the middle classes) - a question that goes beyond the bounds of this article.
Autor, D., L. Katz and A. Krueger (2008), "Trends in U.S. wage inequality: revising the revisionists", The Review of Economics and Statistics, vol. 90, No. 2, Cambridge, Massachusetts, MIT Press, mayo.

Banerjee, A.V. and E. Duflo (2008), "What is middle class about the middle classes around the world?", Journal of Economic Perspectives, vol. 22, No. 2, Nashville, Tennessee, American Economic Association.

Barozet, E. (2006), "El valor histórico del pituto: Clase media, integración y diferenciación social en Chile", Revista de Sociología, No. 20, Santiago, Chile, University of Chile.

Becker, G. (1975), Human Capital: A Theoretical and Empirical Analysis with Special Reference to Education, Chicago, University of Chicago Press.

Bourdieu, P. (1987), La distinción: Criterios y bases sociales del gusto, Madrid, Taurus.

Chauvel, L. (2002), Le destin des générations, structure sociale et cohortes en France au XXe siècle, Paris, Presses Universitaires de France (PUF).

Erikson, R. and J.H. Goldthorpe (1993), The Constant Flux: A Study of Class Mobility in Industrial Societies, Oxford, Oxford University Press.

Espinoza, V. and E. Barozet (2009), “¿De qué hablamos cuando decimos "clase media'? Perspectivas sobre el caso chileno", En Foco, No. 142, Santiago, Chile, Expansiva.

Franco, R., A. León and R. Atria (2007), "Estratificación y movilidad social en América Latina. Una agenda de trabajo", Estratificación y movilidad social en América Latina. Transformaciones estructurales de un cuarto de siglo, R. Franco, A. León and R. Atria (eds.), Santiago, Chile, LOM Ediciones.

Franco, R., M. Hopenhayn and A. León (2011), "The growing and changing middle class in Latin America: an update", CEPAL Review, No. 103 (LC/G.2487-P), Santiago, Chile, April. (2010), "Las clases medias en América Latina: Historias cruzadas y miradas diversas", Las clases medias en América Latina: Retrospectiva y nuevas tendencias, R. Franco, M. Hopenhayn and A. León (coords.), Mexico City, ECLAC-Siglo XXI.

Garretón, M.A. (2007), The Socio-political Matrix and Economic Development in Chile, Manchester, University of Manchester, October.

Glenn, N. (2005), Cohort Analysis, Thousand Oaks, California, Sage Publications.

Kreckel, R. (2006), "On national and global 'middle classes"”, paper prepared for the Indian-German Workshop, University of Munich, 7-8 September.
Leiulfsrud, H., I. Bison and H. Jensberg (2005), Social Class in Europe: European Social Survey 2002/3, Trondheim, Norwegian University of Science and Technology (NTNU).

León, A. and J. Martínez (2001), "La estratificación social chilena hacia fines del siglo XX", Políticas sociales series, No. 52 (LC/L.1584-P), Santiago, Chile, Economic Commission for Latin America and the Caribbean (ECLAC), August. United Nations publication, Sales No. S.01.II.G.127.

Mannheim, K. (1952), "The problem of generations", Essays on the Sociology of Knowledge, K. Mannheim, London, Routledge \& Kegan Paul. Originally published in 1928.

Marx, K. and F. Engels (1989), Contribución a la crítica de la economía política, Moscow, Editorial Progreso. Originally published in 1859 .

Mincer, J. (1974), Schooling, Experience and Earnings, Nueva York, National Bureau of Economic Research.

oECD (Organisation for Economic Cooperation and Development) (2011), Society at a Glance 2011: OECD Social Indicators, OECD Publishing [online] http://dx.doi.org/10.1787/soc_glance-2011-en. (2010), Latin American Economic Outlook 2011. How Middleclass is Latin America? [online] http://www.latameconomy. org/fileadmin/uploads/laeo/Documents/E-book_LEo2011EN_entier.pdf.

Ravallion, M. (2009), "The developing world's bulging (but vulnerable) 'middle class"', Policy Research Working Paper, No. 4816, Washington, D.C., World Bank.

Ryder, N. (1965), "The cohort as a concept in the study of social change", American Sociological Review, vol. 30, No. 6, Washington, D.C., American Sociological Association, December.

Sapelli, C. (2011a), "A cohort analysis of the income distribution in Chile", Estudios de economía, vol. 38, No. 1, Santiago, Chile, University of Chile, June.

(2011b), Chile: ¿Más equitativo? Una mirada distinta a la distribución del ingreso, la movilidad social y la pobreza en Chile, Santiago, Chile, Ediciones Universidad Católica de Chile.

Torche, F. and G. Wormald (2004), "Estratificación y movilidad social en Chile: Entre la adscripción y el logro", Políticas sociales series, No. 98 (LC/L.2209-P), Santiago, Chile, Economic Commission for Latin America and the Caribbean (ECLAC). United Nations publication, Sales No. S.04.II.G.132.

Weber, M. (1964), Economía y sociedad, Mexico City, Fondo de Cultura Económica. Originally published in 1922. 